\title{
Enhancement of fatigue life of rail-end-bolt holes by slide diamond burnishing
}

\author{
J. T. Maximov*, G. V. Duncheva, A. P. Anchev, I. M. Amudjev and V. T. Kuzmanov
}

Department of Mechanical Engineering, Technical University of Gabrovo, 5300 Gabrovo, Bulgaria

\begin{tabular}{|c|c|}
\hline $\begin{array}{l}\text { ART I C LE I NFO } \\
\end{array}$ & A B S T RACT \\
\hline $\begin{array}{l}\text { Article history: } \\
\text { Received June 6, } 2014 \\
\text { Accepted } 17 \text { June } 2014 \\
\text { Available online } \\
19 \text { July } 2014 \\
\text { Keywords: } \\
\text { Rail-end-bolt holes } \\
\text { Fatigue failure } \\
\text { Residual stresses } \\
\text { Cold working } \\
\text { Finite element simulation }\end{array}$ & $\begin{array}{l}\text { The fatigue failure around rail-end-bolt holes is particularly dangerous since it leads to } \\
\text { derailment of trains and consequently to inevitable accidents. It is well-known that the fatigue } \\
\text { life of structural holed components, subjected to cyclic load, can be increased by generating } \\
\text { compressive hoop stresses around the holes. These beneficial residual compressive stresses } \\
\text { significantly reduce the maximum values of the operating tensile stresses arising at the critical } \\
\text { points of the components and thus impede the formation of first mode cracks. A new approach } \\
\text { to enhancement of fatigue life of rail-end-bolt holes has been developed. The approach involves } \\
\text { sequential drilling and reaming through a new combined tool and then slide diamond } \\
\text { burnishing by a new device. The technology implementation was carried out on machine tool. } \\
\text { The process of creating residual stresses has been studied both experimentally and numerically. } \\
\text { The experimental study was conducted by means of a modified split ring method. A reliable } \\
\text { finite element modeling approach to the slide diamond burnishing process was developed. On } \\
\text { this basis, the process was optimized by means of a genetic algorithm. As a result, the optimal } \\
\text { combination of the governing process parameters is established, which ensures both maximum } \\
\text { depth of the compressive zone and maximum absolute values of the residual stresses. }\end{array}$ \\
\hline
\end{tabular}

(C) 2014 Growing Science Ltd. All rights reserved.

\section{Introduction}

Railway transport is acquiring greater significance in the development of modern transport. This tendency is a direct consequence from the energy and environmental crises. In this aspect research directed to higher safety, long life and economy of components composing railways, is becoming more and more topical.

Building of high-speed railway lines is related to the so-called continuously welded rails. However, bolted joint railways cannot be done away with by $100 \%$ - in broken country and curvilinear railroad tracks they have no alternative. There are a large number of bolted rail joints in heavy lines and mountainous lines. In Bulgaria, for instance, bolted joint railroads are $64.4 \%$ of the

* Corresponding author.

E-mail addresses: jordanmaximov@gmail.com (J. T. Maximov) 
railway network and their overall extended length is $4760 \mathrm{~km}$ (Valkov and Grozdanov, 2009). Two joint bars or fishplates and four bolts are used to connect the ends of adjoining rails. When the remaining conditions are the same, reliability, service life as well as maintenance and repair activities depend on the state of components composing rail joints: rail ends, joint bars and bolt connections (Fig. 1). The elements in a rail joint are subjected to cyclic and impact loads as a result of passing of trains (Cai et al., 2007). The dynamic character of loads causes fatigue in material in rail joint components or railway axles and respectively provokes originating and growth of fatigue cracks mostly around the bolt holes or notches, which are natural stress concentrations(Cai et al., 2007, Torabi and Aliha, 2013). A mode of failure in bolted joints is fatigue crack initiation and growth from the bolt holes in the end rail (Fig. 2).

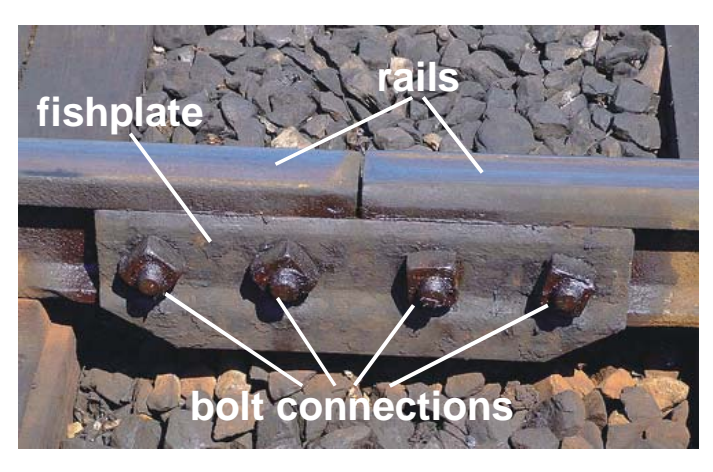

Fig. 1. Bolted rail joint components

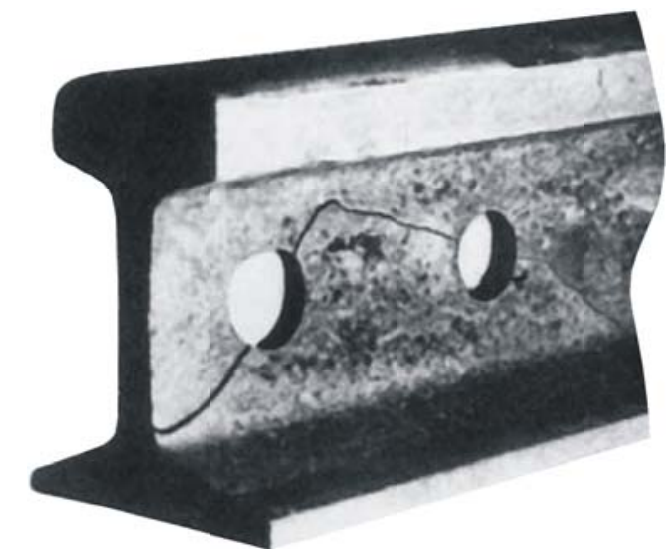

Fig. 2. Typical cracks originating at rail-end-bolt hole

The fatigue failure around rail-end-bolt holes is particularly dangerous since it leads to derailment of trains and consequently to inevitable accidents. And whereas the exploitation of railroads can continue when defects appear in the rail heads, the breaking of rail ends directly jeopardizes the safety of this sort of transport. Therefore, the fatigue failure around bolted holes is of limiting importance to the safety of railway transport, service life and maintenance and repair activities of bolted joint railroads.

It is well-known that the fatigue life of structural holed components, subjected to cyclic load, can be increased by generating compressive normal stresses around the holes. These beneficial residual compressive stresses significantly reduce the maximum values of the operating tensile stresses arising at the critical points of the components and thus impede the formation of first mode cracks.

A common approach to impart beneficial residual stresses around a hole is coldworking. Implementing this approach, the FTI company has developed RailTec system, based on split sleeve cold expansion method and especially adapted to rail-end-bolt holes (Reid, 1993). An approach to enhancement of fatigue life of rail-end-bolt holes, based on the symmetric cold expansion method (Maximov et al., 2013), is developed in (Duncheva \& Maximov, 2013). The implementation of the above two methods requires special equipment.

When the processing of rail-end-bolt holes is performed on machine tools (Fig. 3), another approach is appropriate - taking advantage of the burnishing technologies. The main requirement here is to achieve the maximum depth of the zone of residual compressive stress and a low roughness, while the accuracy of shape and size are irrelevant. Those requirements can be satisfied entirely from slide diamond burnishing. Other advantages of this method are: easy implementation with a relatively low-cost devices; low friction coefficient between the deforming element (artificial diamond) and the hole surface - according to Korzynski (2013) this coefficient is in the range 0.02 to 0.08; high wear resistance. According to Yatzenko (1985) the deforming element durability reaches processed length of $100000 \mathrm{~m}$. 


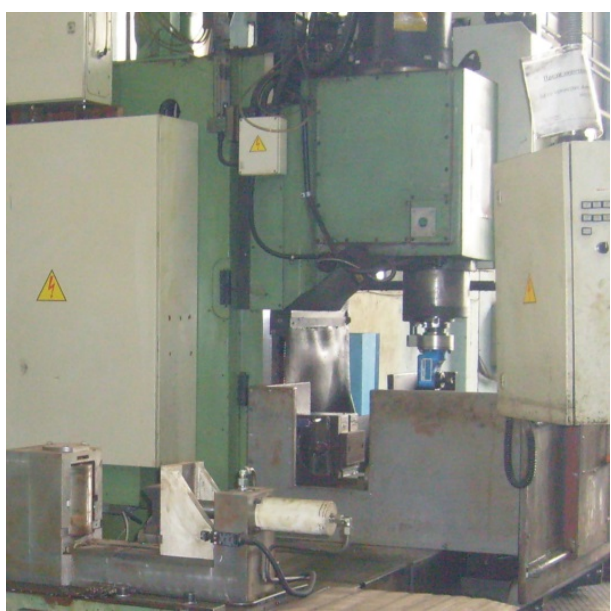

Fig. 3. Processing of rail-end-bolt holes on machine tool in FAE Sofia

To assess the effect of applying the slide diamond burnishing, it is necessary to know in quantitative and qualitative aspect the residual stress distribution around the rail-end-bolt holes. Since the fatigue failure at the rail ends is caused by originating and growth of first mode cracks around the bolt holes, the residual hoop normal stresses are crucial.

Unfortunately, in Bulgaria, as well as in many other countries, the problem of fatigue failure of railend-bolt holes is underestimated and consequently the appropriate treatment of these holes is also underestimated.

The main objective of the study is to find the distribution of beneficial residual normal hoop stresses around rail-end-bolt holes after slide diamond burnishing. To reach the target both experimental and numerical approaches are used.

\section{Experimental part}

\subsection{Rail-end-bolt holes treatment experiment}

In the present study, disc-shaped samples with diameter of $100 \mathrm{~mm}$ and thickness of $17 \mathrm{~mm}$ were used. The work material was steel 76 (equivalent to rail steel R260) with chemical composition shown in Table 1. STAMA vertical machining center was used for both drilling-reaming and diamond burnishing. The experiment was conducted at Impuls JCS - Gabrovo. Special tools (Fig. 4) were designed by the authors and manufactured by "Ceraticit Bulgaria" JCS - Gabrovo.

Table 1. Chemical composition of steel 76 in percentages

\begin{tabular}{|c|c|c|c|c|c|c|c|c|c|c|c|}
\hline $\mathrm{C}$ & $\mathrm{Si}$ & $\mathrm{Mn}$ & $\mathrm{P}$ & $\mathrm{S}$ & $\mathrm{Cr}$ & Мo & $\mathrm{Ni}$ & $\mathrm{Al}$ & $\mathrm{Cu}$ & $\mathrm{Ta}$ & $\mathrm{Fe}$ \\
\hline 0.75 & 0.213 & 0.74 & 0.022 & 0.041 & 0.029 & 0.015 & 0.055 & 0.018 & 0.03 & 0.015 & 98.045 \\
\hline
\end{tabular}

The first four specimens were subjected to drilling and reaming using our combined tool. The manufacturing parameters feed rate and speed were changed in two levels (see Table 2). These parameters were recommended by the manufacturer of carbide inserts.

Table 2. Manufacturing parameters and results

\begin{tabular}{lcccc}
\hline Specimen № & Speed, rpm & Feed rate, $\mathrm{mm} / \mathrm{rev}$ & Diameter size, $\mathrm{mm}$ & Roughness, Ra \\
\hline 1 & 1000 & 0.15 & $33.38 / 33.38$ & 1.50 \\
2 & 1400 & 0.15 & $33.39 / 33.38$ & 2.56 \\
3 & 1000 & 0.2 & $33.38 / 33.37$ & 2.21 \\
4 & 1400 & 0.2 & $33.38 / 33.38$ & 0.39 \\
5 & 1000 & 0.15 & $33.39 / 33.39$ & 0.27 \\
6 & 1400 & 0.15 & $33.40 / 33.39$ & 0.27 \\
7 & 1000 & 0.2 & $33.39 / 33.39$ & 0.38 \\
\hline
\end{tabular}


The following four specimens were successively subjected to drilling and next reaming through our combined tool, and next diamond burnishing with the same manufacturing parameters. The burnishing tool was constructed for bilateral processing. The radius of the spherical diamond tip was $r=1 \mathrm{~mm}$. Burnishing force of $400 \mathrm{~N}$ was applied.

The obtained holes roughness has been measured using a Mitutoyo surftest-4 instrument. Each experimental value of the roughness has been obtained in the following way: the measurement was taken on three generatrixes situated at $120^{\circ}$ as for each generatrix the mean value of the roughness has been given. The final value of the roughness has been found as an arithmetic mean of the obtained roughness for the three generatrixes. To evaluate the shape deviation, the diameters of the processed holes have been measured in the two sections.

On the basis of the results obtained (Table 2) the following comments can be made with respect to the influence of the process manufacturing parameters:

- In the previous processing (by cutting), the roughness depends on the process parameters: by increasing the feed rate, it deteriorates; by increasing the speed, the roughness weakly deteriorates

- Despite the different initial conditions, after diamond burnishing, the obtained roughness is practically constant, and the reduction in the average roughness compared to the previous treatment is about 6 times.
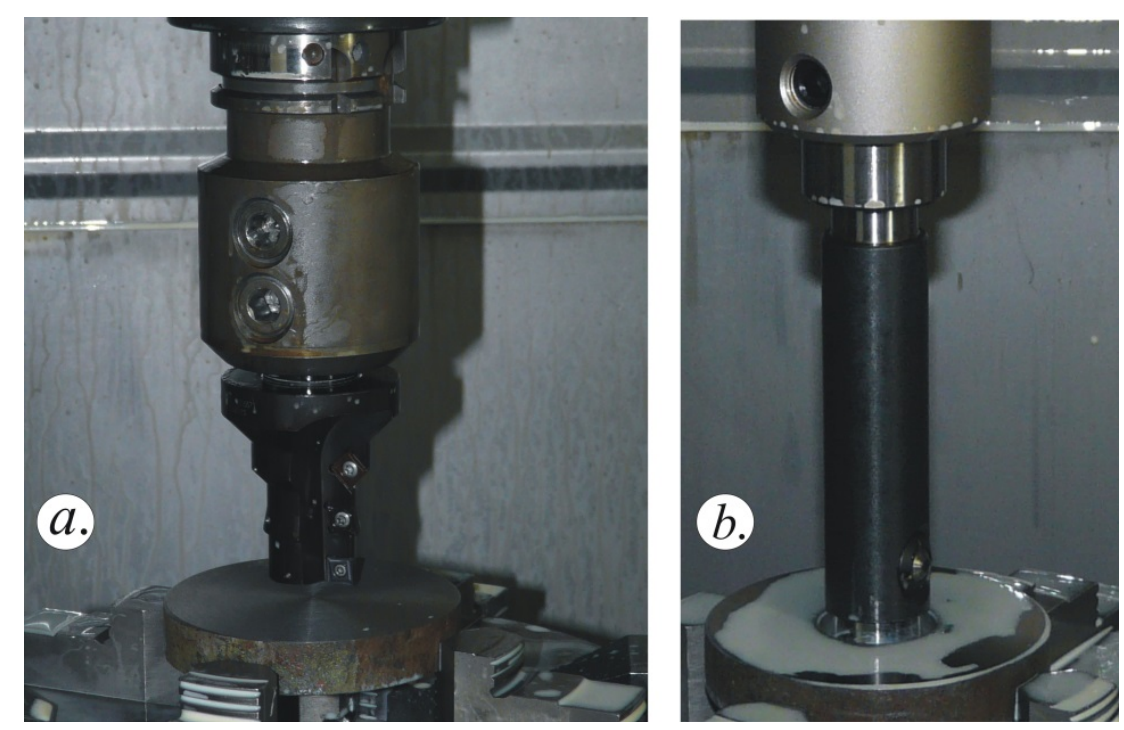

Fig. 4. New tool setup: a. drill-reamer; b. slide diamond burnishing tool

\subsection{Residual stress determination}

\subsubsection{Nature of the employed method}

It is well-known (Fattouh and El-Khabeery, 1989) that the generated zone with beneficial residual stresses after burnishing covers only the surface layers. One of the most used experimental methods for measurement of residual stresses is the x-ray diffraction (Webster and Ezeilo, 2001). This method is frequently used in cases of cold expanded holes (Maximov et al., 2009; 2012; 2014). However, to measure the residual hoop stresses around diamond burnished holes, the x-ray diffraction method is inapplicable for two main reasons:

- the diameter of the x-ray beam is commensurate with the depth of the compressive zone, and therefore, the residual stresses can not be measured in the available front surfaces; 
- the x-ray beam can not be directed tangentially to the hole surface.

Of the other experimental methods, the stress relief approach is suitable for this case. An object of measurement are the residual circumferential normal stresses $\sigma_{t}^{\text {res }}$ (stresses of first type) which have a decisive role for the fatigue life of rail-end-bolt holes. The stress relief approach has been used. The latter is based upon the following assumption that the removal of a part of the specimen is equivalent to applying a distributed load to its remaining part and the load intensity is equal to the magnitude of residual stresses but has an opposite sign. This load causes deformation whose magnitude is used for calculating $\sigma_{t}^{\text {res }}$.

Three basic methods implement this idea. Chronologically, the first known method belongs to Zaks (1924). He developed a method for determination of residual stresses in thin-walled tubes. The method requires considerable accuracy of measurement of the linear changes since the deformations of the pipes are very small when thin layers are removed from the samples. Significantly more effective is the method developed by Davidenkov (1931), in which the tube is pre-cut along to one generatix. Thus, the obtained bending deformations are much higher in comparison with those of the Zaks' method. Deflection etching technique is based on removal of thin layers of stressed material from the machined surface region by electrochemical action (Sadat, 2012). This method was first developed by Frisch and Tompsen (1951) and later was used by many researchers (Sadat and Bailey, 1985; Fattouh and El-Khabeery, 1989; El-Khabeery and Fattouh, 1989; El-Axir, 2000, 2002; Belgasim and El-Axir 2010).

Over the years many modifications of the three methods have been developed. On the physical basis of the Davidenkov's method, Birger (1963) modified Davidenkov's "split ring" method, and Vitman (1935) developed a simplified methodology. These methods are now widely used in Russia. In the present study a modification of the "split ring" method has been applied (Fig. 5). Removing layers is performed chemically, and the calculation of residual stresses is made for the lines of the centers of gravity of the removed layers through an incremental way.

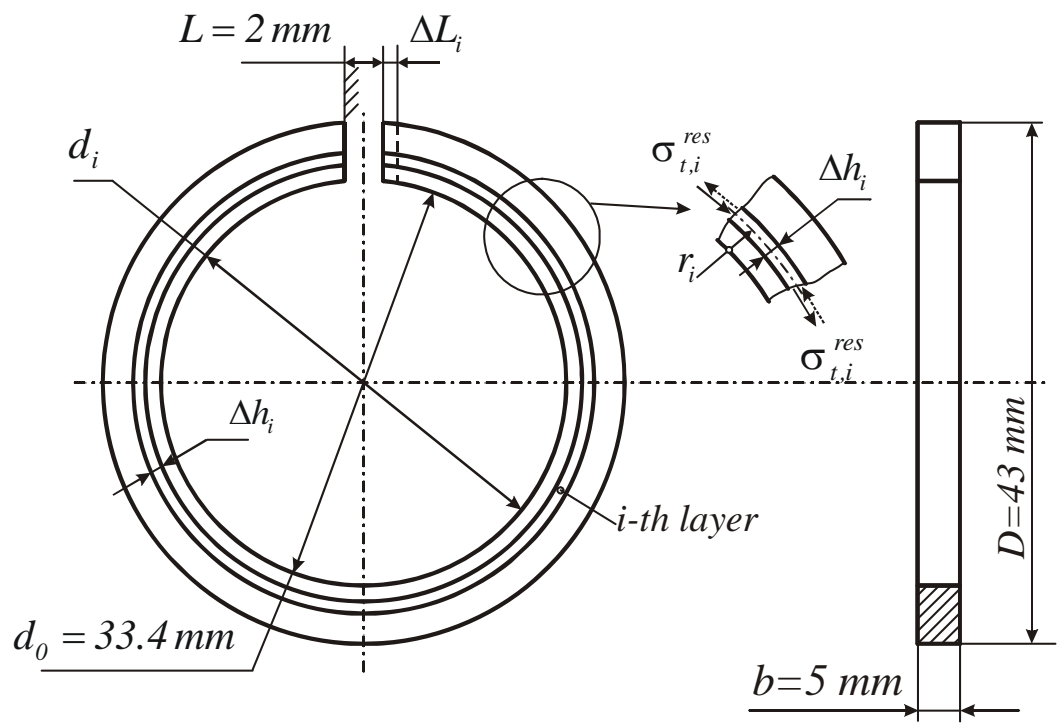

Fig. 5. A scheme of the split ring method

The hoop stress $\sigma_{t, i}^{*}$ in the $\mathrm{i}$-th layer, immediately before removal is:

$\sigma_{t, i}^{*}=\sigma_{t, i}^{r e s}+\sigma_{t, i}^{(1)}+\sigma_{t, i}^{(2)}+\sigma_{t, i}^{(3)}$,

where: 
$\sigma_{t, i}^{r e s}$ is the true (original) stress in the i-th layer; $\sigma_{t, i}^{(1)}, \sigma_{t, i}^{(2)}$ and $\sigma_{t, i}^{(3)}$ are additional stresses in the i-th layer caused, respectively, by: the cutting of the ring with a width of $b$, the cutting of the ring in the direction of its radius and the removal of the previous number of layers;

$$
\sigma_{t, i}^{(2)}=2 \frac{E \Delta D_{c u t}}{D_{\text {aver }}^{2}}\left(\frac{h}{2}-r_{i}\right),
$$

where $E$ is Young's modulus, $D_{\text {aver }}$ is the average diameter of the ring, $\Delta D_{\text {cut }}$ is the change in the average diameter of the ring due to cutting the ring in the direction of its radius; $h$ is the semidifference between the outer and inner diameter of the ring before cutting; $r_{i}$ is the distance between the hole edge (before start of the experiment) and the line of the centers of gravity of the i-th layer;

$r_{i}=\frac{1}{2} \Delta h_{i}+\sum_{j=1}^{i-1} \Delta h_{j}$,

$\Delta h_{i}$ is the thickness of the $\mathrm{i}$-th layer;

$\sigma_{t, i}^{(3)}=\frac{2 E}{3 D_{\text {aver }}^{2}}\left[2\left(h-r_{i}\right) \Delta D_{i-1}-\sum_{j=1}^{i-1}\left(\Delta D_{j} \Delta h_{j}\right)\right]$,

$\Delta D_{i-1}$ is the alteration of the outer diameter of the ring, after removal $i-1$ of a number of layers;

$\sigma_{t, i}^{*}=-\frac{1}{3} \frac{E\left(h-r_{i}\right)^{2}}{D_{\text {aver }}^{2}} \frac{\Delta D_{i}}{\Delta h_{i}}$,

$\Delta D_{i}=\frac{\Delta L_{i}-\Delta L_{i-1}}{\pi}$

$\Delta L_{i}$ is the change of the size $L$ after removal of the $\mathrm{i}$-th layer.

In our case, $\sigma_{t, i}^{(1)}=0$, since the samples were initially cut to the appropriate width.

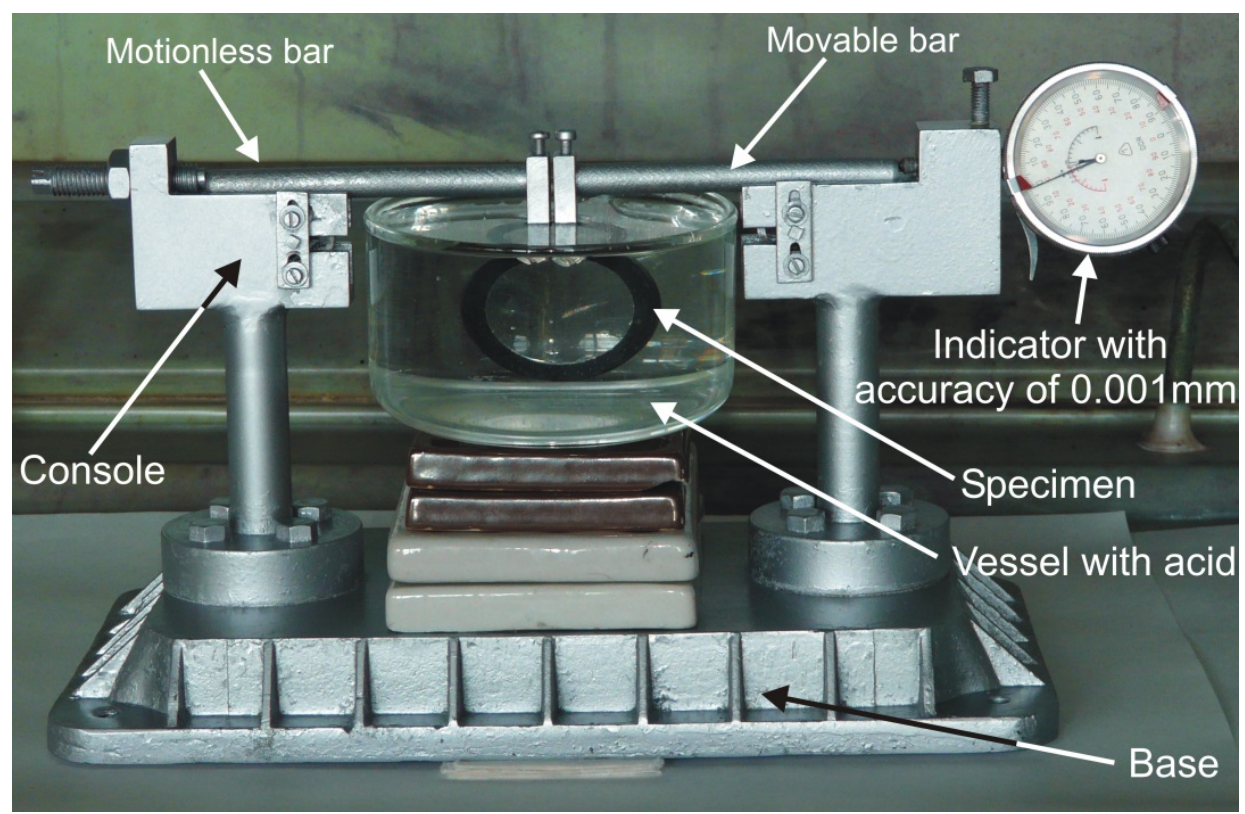

Fig. 6. Experimental set-up for measurement of the residual stresses

\subsubsection{Details of the experiment}

The experimental set-up is shown in Fig. 6. The specimens, made of rail steel 76, were produced by means of a technology which removes all residual stresses except those created by the combined 
tool and the diamond burnishing. The work material has been received in the form of a cylindrical bar and machined into disc-shaped specimens with outer diameter of $44 \mathrm{~mm}$. The width of each specimen is $b=5 \mathrm{~mm}$. After machining, the specimens were annealed at $550{ }^{\circ} \mathrm{C}$ for 2.5 hours and then furnace-cooled to ambient temperature.

The holes of all four samples were processed using the combined instrument, by the procedure described in section 2.1. The manufacturing parameters were: feed rate $0.2 \mathrm{~mm} / \mathrm{tr}$; speed $1000 \mathrm{rpm}$. The openings of two of the samples were processed by diamond burnishing with the same manufacturing parameters.

One sample of each of the two groups was cut radially with a disk cutter of $2 \mathrm{~mm}$ thickness. Subsequently, each of the two uncut samples were placed in a bath of $20 \%$ solution of nitric acid. The surfaces which were not subjected to etching were covered by acid resistant varnish. At equal intervals of time $\Delta t_{i}$ in the process of chemical etching of the samples, the etched layer thicknesses $\Delta h_{i}$ of the reference uncut specimens were measured. Then, for the remaining two slit samples (one with a diamond burnished hole; a hole in the other treated only with cutting), for the same time intervals, deviations $\Delta L_{i}$ were measured according to Fig. 5. For this purpose, an indicator with accuracy of $0.001 \mathrm{~mm}$ was used.

\subsubsection{Experimental results}

The final results for the residual hoop stress distribution are shown in Fig. 13, and the corresponding comments are made in Section 4.

\subsection{Indentation test}

\subsubsection{Nature of the approach}

In order to obtain a reliable FE model of the diamond burnishing process, apart from a realistic geometry and interactions, an adequate constitutive model of the behavior of the workpiece surface layers is also needed.

The constitutive model defines the dependence between stress and strain tensors. In the burnishing theory the "flow stress" concept is used to give this dependence for the surface layer in the plastic field. The burnishing process acts on the surface layer of the workpiece. This behaviour of this layer may considerably differ from the bulk material, because of the existence of large plastic strains, as well as specific micro-profiles and other effects created in the production of the workpiece. For these reasons the conventional testing methods for stress-strain curve determination by a one-dimensional test, as well as the corresponding cyclic tests, can be applied to the bulk material, but not to the surface layer. For the surface layer this dependence in the plastic field must be determined in a manner that corresponds to the actual loading of this layer.

Methods for modeling a constitutive model of the processes roller burnishing and spherical motion burnishing (SMB) are developed, respectively in (Sartkulvanich et al., 2007; Yen et al., 2005; Maximov and Duncheva, 2012). Rolling friction exists in the roller burnishing, while sliding friction exists in both processes -SMB and diamond burnishing. Nevertheless, diamond burnishing is very similar to roller burnishing, due to the low coefficient of friction between the diamond and the steel. 

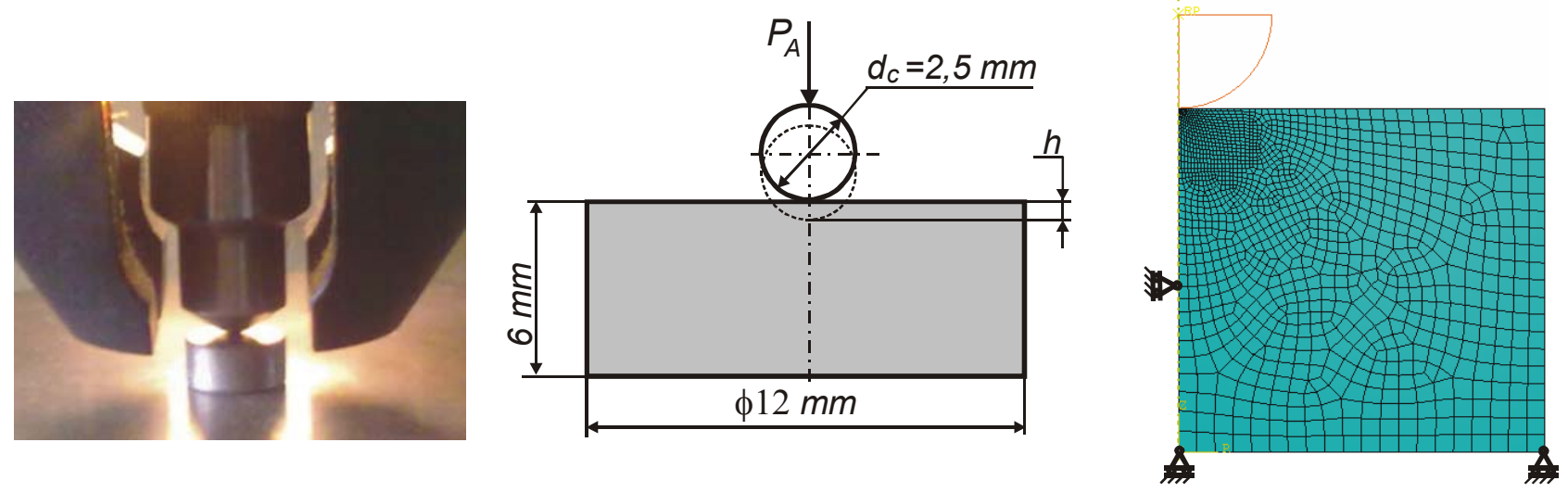

Fig. 7. Photo, scheme and FE model of the indentation test

That is why, in this study, a modified embodiment of the method shown in (Sartkulvanich et al., 2007) is applied for obtaining a constitutive model of the diamond burnishing. The experimental part of the approach is a test, similar to the method for measuring Brinell hardness. Spherical tip with diameter of the sphere $d_{\text {sph }}=2.5 \mathrm{~mm}$ is pressed in the specimen under the action of axial force $P_{A}$ (Fig. 7). The dependence $P_{A}=P_{A}(h)$ is determined, where $h$ is the depth of the ball mark. FE analysis of the mechanical test aims to establish the relationship stress-strain in the plastic field. This dependence is presented in the form:

$\sigma=\sigma_{Y}\left(1+\frac{E}{\sigma_{Y}} \varepsilon_{P}\right)^{n}$,

where $\sigma$ is the flow stress, $\sigma_{Y}$ is the yield limit, $E$ is Young's modulus, $\varepsilon_{P}$ is the plastic strain, and $n$ is the strain hardening for a one-dimensional stressed state.

FE simulation of the mechanical test is carried out repeatedly, each time with different combinations of $\sigma_{Y}$ and $n$ in the model (5), and from the FE results for each combination the dependence "axial force-depth of the ball imprint" is determined. This dependence is compared with the experimental one $P_{A}=P_{A}(h)$. Variation with the pair $\sigma_{Y}$ and $n$ continues until the difference between the experimental and the FE dependencies is minimized.

However, Eq. (5) describes hardening in the plastic field in conditions of a 1-D stressed state and it is assumed that Eq. (5) is valid for all possible loading paths and stressed states. In fact, the deforming process is a 3-D process. This cyclic loading causes deformation anisotropy; that is irregular expansion and movement of the yield surface in the stressed space. That is why, taken alone, Eq.n (5) is not sufficient to define the material's constitutive model. In fact non-linear kinematic hardening law must be added

$\dot{\alpha}_{i j}=\frac{C}{\sigma^{0}} \sigma_{i j}^{a} \dot{\bar{\varepsilon}}_{p}^{e q}-\gamma \alpha_{i j} \dot{\bar{\varepsilon}}_{p}^{e q}$,

where $\sigma^{0}$ is the equivalent stress defining the size of the yield surface, whose initial value is $\left.\sigma\right|_{0}$ - equivalent stress defining the size of the yield surface at zero plastic strain $\left(\sigma^{0}\right.$ is determined through a one-dimensional test and it is assumed that $\sigma^{0}$ is valid for all possible stressed states and loading paths; thus $\sigma^{0}$ is the flow stress and $\left.\sigma\right|_{0}$ is the yield limit $\left.\sigma_{Y}\right) ; \bar{\varepsilon}_{p}^{e q}$ is the equivalent plastic 
strain; $\alpha_{i j}$ is a micro-stress tensor (back stress tensor); $C$ is the initial kinematic hardening modulus; $\sigma_{i j}^{a}=\sigma_{i j}-\alpha_{i j}, \sigma_{i j}$ is a stress tensor; $\gamma$ is the coefficient which determines the rate of decreasing the kinematic modulus with increasing the equivalent plastic strain $\bar{\varepsilon}_{p}^{e q}$.

\subsubsection{Experimental result}

The indentation test was carried out at laboratory Testing of Metals at the Technical University of Gabrovo. The experimental result from the indentation test is shown in Fig. 8.

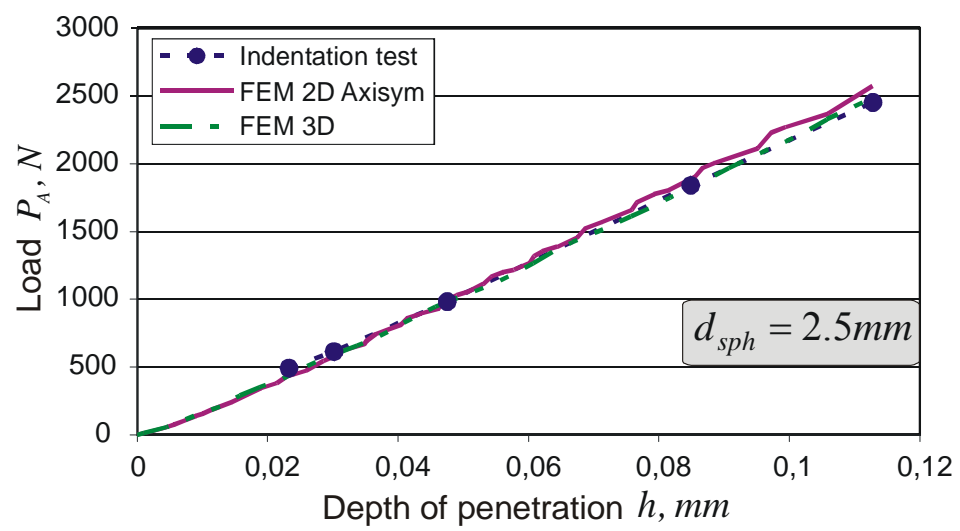

Fig. 8. Comparison of the load-depth curve between FEM simulation and indentation test of steel 76

\section{Finite element simulation}

\subsection{FE models of burnishing process}

While burnishing is a 3D process, the possibily to use 3-D FEM in its modelling are limited due to the extremely large computational times required to run these simulations. This problem is exacerbated by the requirement to model the initial roughness (before burnishing). The task size can be reduced by increasing the size of the finite elements used in the simulations, especially for the surface layer; however, this approach significantly reduces the solution accuracy. Conversely, 2-D FEM (plane strain) allows precise modelling of the geometry of the surface layer.

The existing FEM studies of the burnishing process relate to the ball and roller burnishing of external cylindrical surfaces. One of the first FEM studies was performed by Roettger (2005). In this two-dimensional (2-D) plane strain FEM approach a rigid ball exerts compression on a rough surface of the workpiece until the compression force reaches a prescribed magnitude. After that the ball raises and moves to a distance $f$ that is equal to the feed rate. Yen et al. (2005) further improved the basic 2-D model and also developed a three-dimensional (3-D) model. In these models a displacement control was used as a time curve for a tool's normal displacement to the workpiece. On the basis of a comparison of the residual stresses results obtained from 2-D and 3-D FEM models with experimental results, Yen et al. (2005) established that the 2-D model was able to more closely reproduce the observed experimental values. These models were further developed by Sartkulvanich et al. (2007). FEM of the burnishing of AISI1042 steel, in order to determine the displacements of the roughness peaks, was developed by Sai and Sai (2005). A 3-D FE study of the burnishing process in which the thermo-mechanical nature of the process was taken into account was performed in (Deng et al., 2004). A focus of that paper was the influence of the burnishing parameters on the residual stresses and it was established that the influence of the velocity strain is only minor. A 3D FEM model of the low plasticity burnishing (LPB) process was used by Zhuang and Wicks (2004) to study the residual stresses in a plate of IN 718. In order to mimic the character of the LPB process the ball 
was made deformable in the FEM model and the initial micro-profile of the plate's surface layer was not modelled. Klocke et al. (2011) used the FE approach (without modelling the initial micro-profile) in combination with fatigue tests to study the residual stresses and fatigue behaviour of samples made of IN 718 and Ti-6Al-4V. Attention was focused on the significance of the low hardening on the validity of the FE model, the authors used a combined hardening - non-linear isotropic/kinematic approach. 2-D plain strain FE model of the SMB process was developed by Maximov and Duncheva (2012) on the basis of an approximated kinematic theory of the process. In the present study both 2-D plain strain and 3-D FE models with displacement control have been developed. These models have a different philosophy - while the 2-D model defines a discontinuous contact only by a generatrix of the hole (like the famous models developed by Rotger (2002) and Yen et al. (2005)), the 3-D model defines sliding friction in circumferential direction, imitating diamond burnishing.

\subsection{Material constitutive model}

\subsubsection{FE model of the indentation test}

ABAQUS/Standard and axisymmetric FE model were used (Fig. 7). The deforming ball is modeled as a rigid body, and for the sample linear quadrilateral finite elements, type CAX4R are used. Displacement of the ball represented by the so-called "reference point (RP)" is set and, as a result, the reaction at this point is found. This reaction corresponds to the load $P_{A}$ and the displacement corresponds to the depth of penetration $h$. A normal contact (allowing separation) and a tangential frictionless one between the ball and the sample are defined. Preliminary simulations with different coefficients of friction and without friction, showed virtually identical results.

\subsubsection{FE outcomes}

The simulations were performed with different combinations of $\sigma_{Y}$ and $n$. By means of the least squares method the combination is found, for which the difference between the experimental curve and the FEM result is minimum (Fig. 8). It is obtained: $\sigma_{Y}=695 \mathrm{MPa} ; n=0.105$. Eq. (5) can be written as:

$\sigma=695\left(1+296.403 \varepsilon_{P}\right)^{0.105}$

As shown in Fig. 8, the predicted FEM load-depth curve matches very well with the experimental one. Fig. 9 shows a comparison of the flow stress obtained from inverse FEM analysis and onedimensional tests - tensile and compressive, which were conducted at laboratory Testing of Metals. Obviously there is considerable difference between the behavior of the surface layer material and this of the bulk material.

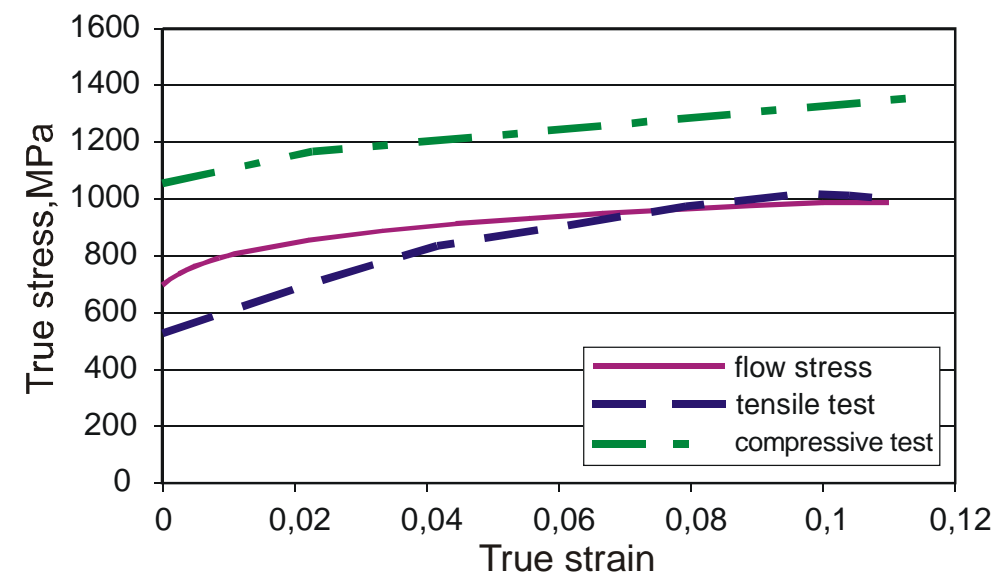

Fig. 9. Comparison of the flow stress obtained from inverse FEM analysis and one-dimensional tests 

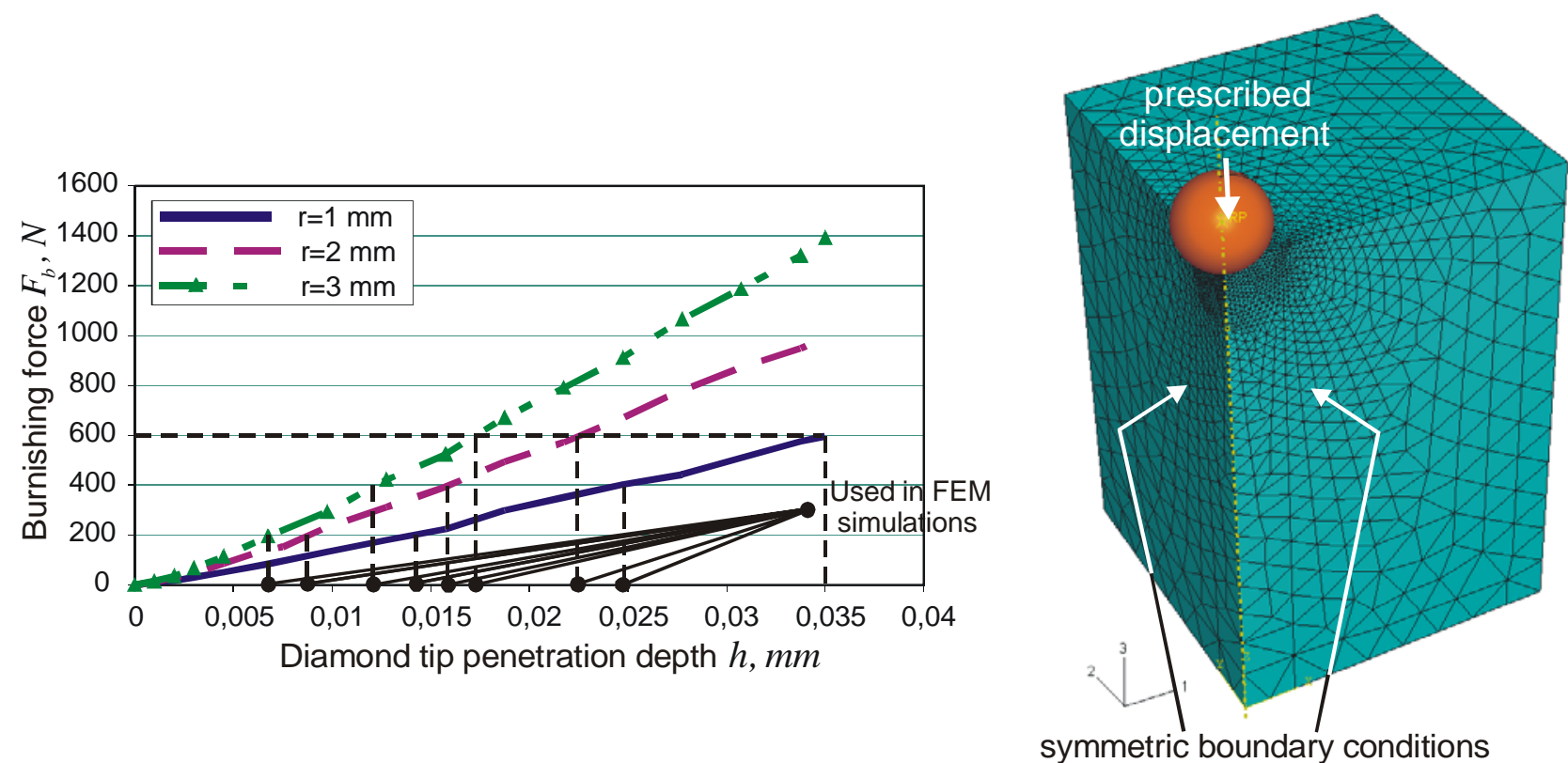

Fig. 10. Establishing the relationship "burnishing force versus depth of penetration"

\subsection{Burnishing force versus depth of penetration}

In this study, diamond burnishing FEM models are based on displacement control. For determination of the dependence $F_{b}=F_{b}\left(d_{P}\right)$, where $F_{b}$ is burnishing force (pressing force of the diamond tip to the workpiece surface) and $d_{P}$ is depth of penetration, a 3-D FE model is designed (Fig. 10). The spherical diamond tip is modeled as a rigid body with three sizes radii $-1 \mathrm{~mm}, 2 \mathrm{~mm}$ and $3 \mathrm{~mm}$. From the workpiece, starting at the surface layer of the hole, a body with sizes $16 \times 16 \times 12 \mathrm{~mm}$ is cut. Since the diameter of the rail-end-bolt hole is considerably larger than the diamond tip diameter, the workpiece object is assumed to be flat. Due to the symmetry, a quarter of workpiece has been taken. This part is discretized with 36578 FEs - type linear tetrahedron C3D4. The material constitutive model is in accordance with Equation 7. Displacement of the ball through the so-called "reference point" is defined, and the result is sought as a reaction to the same point. This reaction corresponds to the burnishing force and the displacement - to the depth of penetration. A normal and frictionless tangential contact between the deforming sphere and workpiece has been defined.

A total of three simulations were conducted - with radii respectively $1 \mathrm{~mm}, 2 \mathrm{~mm}$ and $3 \mathrm{~mm}$. FEM outcomes are shown in Fig. 10.

The developed inverse FE analysis procedure was also tested by means of a 3-D FE model, depicted in Fig. 10. The predicted load-curve matches very well with the experimental curve (see Fig. 8).

\subsection{3-D FE model for establishing residual hoop stress distribution}

The modeled slide diamond burnishing process has the following manufacturing parameters: feed rate $f=0.2 \mathrm{~mm} / \mathrm{rev}, F_{b}=400 \mathrm{~N}$. The previous hole treatment by cutting has the same feed rate. The surface layer obtained after cutting has a mean roughness $R a=2.2 \mu \mathrm{m}$ (according to Table 2), which corresponds with roughness depth $R z=6.4 \mu \mathrm{m}$. The initial roughness is modeled in order to achieve a more realistic representation of the workpiece geometry. In the present study, the burnishing speed factor is not analyzed, considering the adopted constitutive model, which is obviously time-independent. From the viewpoint of mechanics of materials, this factor directly 
affects the strain velocity tensor. Many authors (e.g. El-Axir, 2000; Deng et al., 2004), however, prove that the least influence on the obtained roughness and residual stress distribution has precisely the speed factor. Therefore, its neglecting will not significantly influence the FEM results.

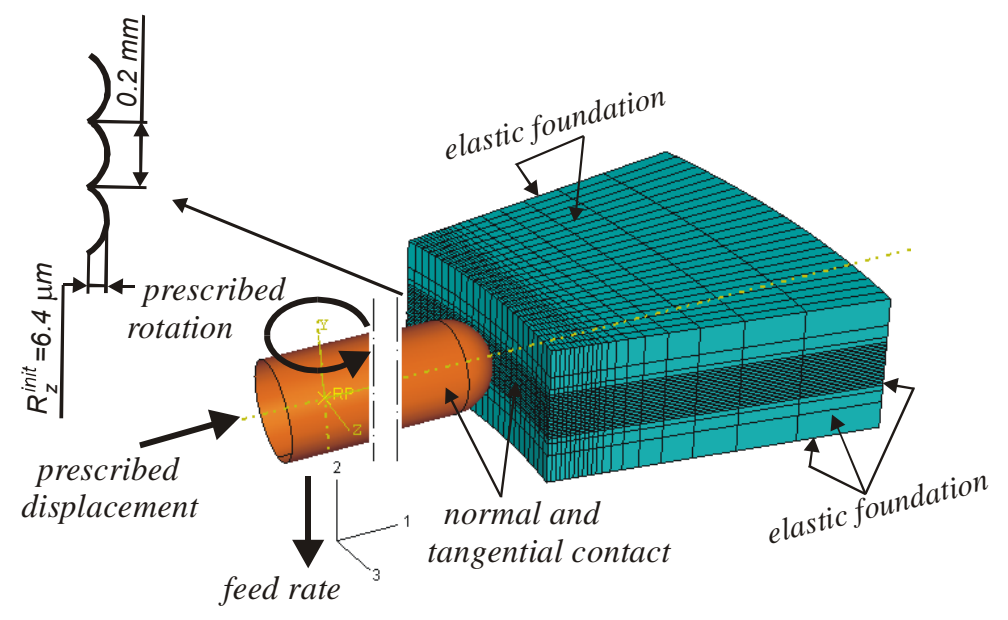

Fig. 11. 3D FE model of the slide diamond burnishing process

A 3-D FE model, shown in Fig. 11 has been developed. The deforming diamond component (having radius $r=1 \mathrm{~mm}$ ) is modeled as a rigid body. From the workpiece, starting at the surface layer of the hole, a body with approximate sizes $4 \times 7 \times 8 \mathrm{~mm}$ has been cut by a cylindrical surface and two pairs of parallel planes. The modeled portion of the workpiece is discretized with 13000 eight-nodal hexahedral FEs (type C3D8R) with a total of 14742 nodes. A normal and tangential contact with friction coefficient of 0.05 between the deforming diamond tip and the workpiece has been defined.

On the free faces of the analyzed portion a contact "elastic foundation" is defined with a coefficient numerically equal to the Young's modulus. Thus, the interaction of the modeled cut out section with the rest of the rail is taken into account. The tool makes a total of 10 cycles and for each next cycle moves against the y-axis at a distance $0.1 \mathrm{~mm}$ (half of the feed rate), as the diamond burnisher tool is designed for two-way operation. The working stroke of the tool is defined by rotation around the axis $\mathrm{y}$ (axis of the hole). In order to facilitate the analysis and to simplify the boundary conditions, every stroke of the tool is performed in a separate analysis (which corresponds to a separate model in ABAQUS), and the results in displacements, stresses and strains, generated in the n-th analysis, define the initial conditions for the $(\mathrm{n}+1)$-th analysis.

The result for the residual stresses distribution was considered in the nodes, lying on the intersection of the two planes of symmetry of the modeled portion of the workpiece.

\subsection{2-D FE model for establishing residual hoop stress distribution}

A plane strain 2-D FE model has been used (Fig. 12). The modeled portion of the workpiece, comprising the surface layer, has dimensions $8 \times 8 \mathrm{~mm}$. This portion lies in a plane containing the hole axis. According to Sartkulvanich et al. (2008) the importance of the geometric factor is greatly reduced when the modeled part has dimensions greater than $5 \times 4.5 \mathrm{~mm}$. The diamond tip is modeled as a rigid body. Plane strain quadrangular finite elements (type CPE4R) - a total of 2676 with 2761 nodes, were chosen. The analysis was conducted in 20 steps and each step corresponds to one cycle of the impact of the deforming sphere on the workpiece. One cycle includes: displacement of the tool to the workpiece to achieve the maximum penetration $d_{p}$; return of the tool to the starting position; moving the tool along the hole axis at a distance of $f / 2=0.1 \mathrm{~mm}$. A normal and tangential contact between the deforming tool and the workpiece was defined. In the absence of a relative tangential 
displacement, the tangential contact is frictionless. The geometrical boundary conditions are depicted in Fig. 12. On the deforming sphere were imposed two types of geometric boundary conditions: a constant (zero rotation) and a time-dependent one (displacements which perform the cycles). For each cycle, a tabular function of the displacements was defined. All functions were synchronized in pseudo-time.The results for the residual stress distribution were considered in the nodes lying on the $x$ axis.
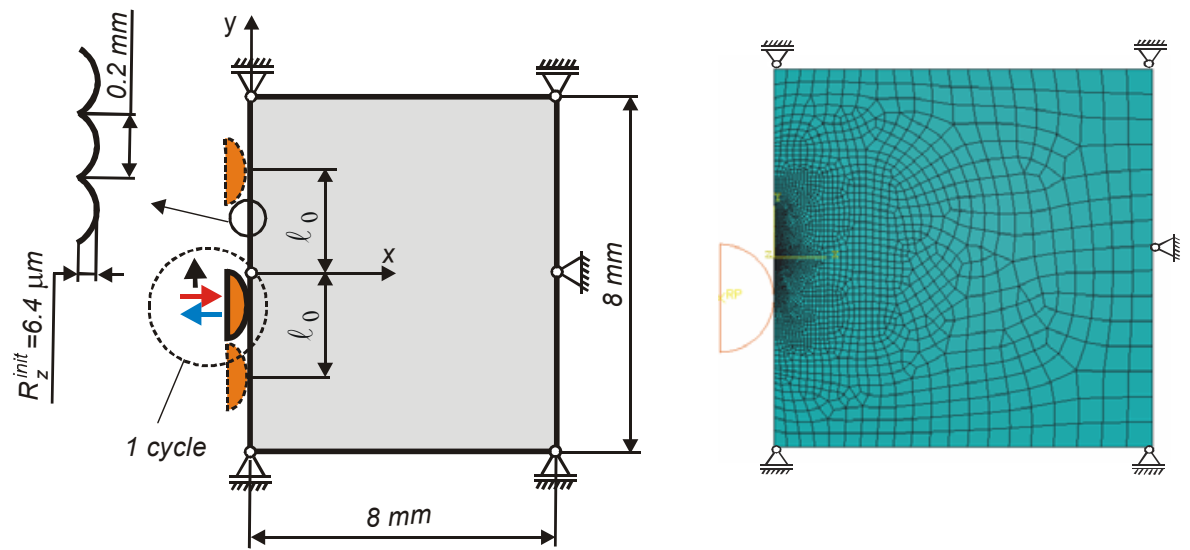

Fig. 12. Plane strain FE model of the slide diamond burnishing process

\section{Residual stresses - results and discussions}

\subsection{Residual stress distribution - experimental and FEM results}

Fig. 13 shows a comparison between the results for residual stress distribution, obtained by an experiment and FE simulations. A 2-D FE simulation predicts the residual hoop stresses in satisfactory agreement with the experimental outcomes with respect to maximum compressive stress. However, the depth that contains compressive residual stresses predicted by the experiment is smaller than the results from the FE simulations. The reason is that the used experimental method is effective for very small depths. Since for the case this experimental method is essentially free of an alternative from the viewpoint of the other experimental methods, the only option for reliable information are the adequate KE simulations. As a whole, the results of a 2-D FE simulation are closer to the experiment in terms of the maximum compressive stress. Although seemingly a 3-D FE model is more realistic and closer to the real process, it is far less practical due to the large resources of time and memory that this model requires. For these reasons, a 2-D FE model is preferred in the following simulations. It has been proven (Sartkulvanich et al., 2007) that the initial residual stresses from cutting have a insignificant effect on the residual stresses obtained by burnishing. For this reason in the present study these stresses are not measured experimentally and are neglected in the FE simulations.

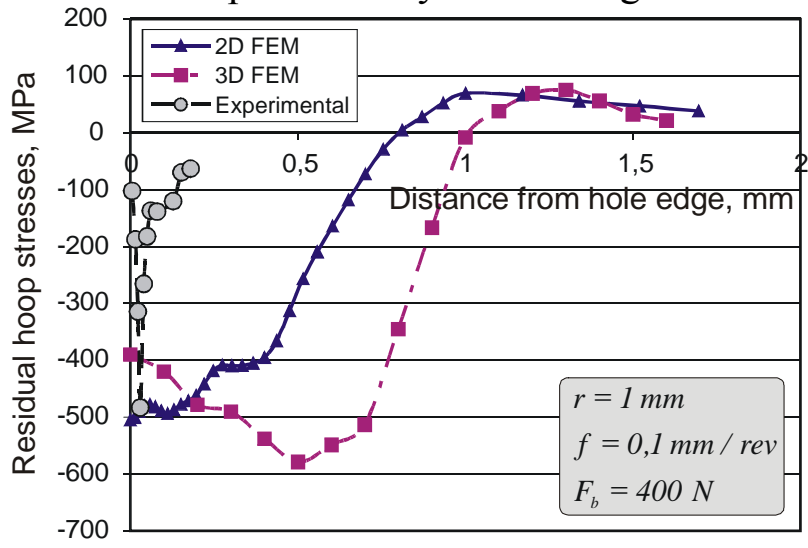

Fig. 13. Residual hoop stress distribution from experiment and FEM simulation, for $F_{b}=400 \mathrm{~N}$,

$$
f=0.2 \mathrm{~mm} / \mathrm{rev}, r=1 \mathrm{~mm}
$$




\subsection{FE parametric study of the residual stress distribution}

The established 2-D FEM is more practical and convenient to study the basic slide diamond burnishing parameters (radius of the spherical diamond tip, burnishing force and feed rate) on the residual hoop stress distribution. One-factor-at-the time method was used.

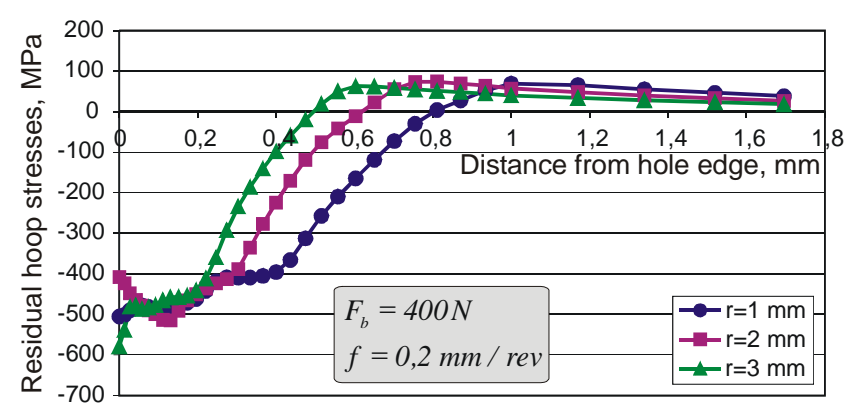

Fig. 14. Effect of diamond tip radius on residual hoop stress distribution, for $F_{b}=400 N$ and $f=0.2 \mathrm{~mm} / \mathrm{rev}$

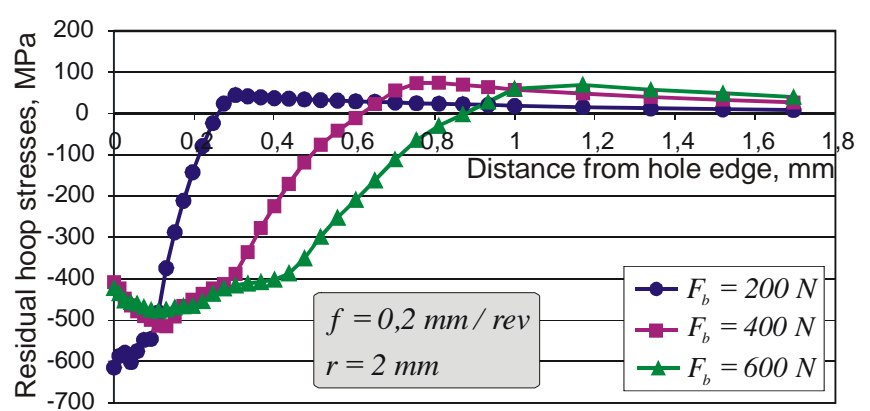

Fig. 15. Effect of burnishing force on residual hoop stress distribution, for $f=0.2 \mathrm{~mm} / \mathrm{rev}$ and $r=1 \mathrm{~mm}$

Fig. 14 shows the residual hoop stress distribution when using different radius of the spherical diamond tip and the same burnishing force and feed rate. The increase of the radius leads to a reduction in the depth of the compressive zone. However, there is a tendency for a slight increase in the absolute value of the maximum compressive residual stress. The residual hoop stress distribution for a different burnishing force and constant radius and feed rate is depicted in Fig. 15.

The increase in the burnishing force leads to an increase in the depth of the compression zone while the absolute value of the maximum compressive residual stress decreases.

Fig. 16 shows the residual hoop stress distribution when using different feed rate and the same burnishing force and radius. There is a tendency of increasing the depth of the compressive zone and the absolute value of the maximum compressive residual stress. For values of feed rate larger than 0.2 , this trend is significantly decreased. Among the three parameters, the burnishing force has the biggest influence on the residual stresses and the feed rate has the least.

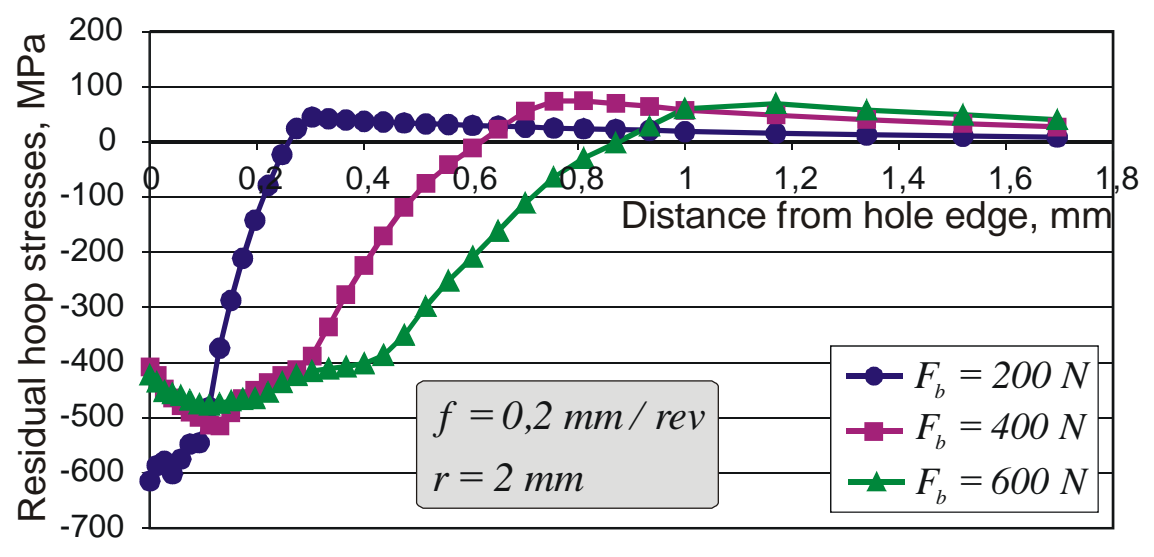

Fig. 16. Effect of burnishing feed rate on residual hoop stress distribution, for $F_{b}=400 \mathrm{~N}$ and

$$
r=1 \mathrm{~mm}
$$

\section{FEM optimization of slide diamond burnishing of rail-end-bolt holes}

The developed 2-D plane strain FEM model can be used for optimization of the slide diamond burnishing of rail-end-bolt holes in terms of the characteristics of the zone with residual compressive hoop stresses - maximum depth and the maximum absolute value of compressive residual stress. An 
optimal composed second-order design was chosen to guide the numerical experiments (Table 3). The features of interest in this study are the depth of the compressive field $d_{c}$ and the maximum absolute value of the residual hoop stresses $\max \sigma_{t}^{\text {res }}$.

Table 3. Optimal composed second-order design

\begin{tabular}{|c|c|c|c|c|c|}
\hline Set & $x_{1}$ & $x_{2}$ & $x_{3}$ & $Y_{d_{c}}, m m$ & $Y_{\max \sigma_{t}^{r e s}}, M P a$ \\
\hline 1 & -1 & -1 & -1 & 0.436 & 485 \\
\hline 2 & +1 & -1 & -1 & 0.184 & 617 \\
\hline 3 & -1 & +1 & -1 & 0.975 & 501 \\
\hline 4 & +1 & +1 & -1 & 0.655 & 578 \\
\hline 5 & -1 & -1 & +1 & 0.485 & 494 \\
\hline 6 & +1 & -1 & +1 & 0.173 & 614 \\
\hline 7 & -1 & +1 & +1 & 1.1 & 544 \\
\hline 8 & +1 & +1 & +1 & 0.75 & 560 \\
\hline 9 & -1 & 0 & 0 & 0.811 & 504 \\
\hline 10 & +1 & 0 & 0 & 0.5 & 580 \\
\hline 11 & 0 & -1 & 0 & 0.255 & 614 \\
\hline 12 & 0 & +1 & 0 & 0.88 & 478 \\
\hline 13 & 0 & 0 & -1 & 0.55 & 483 \\
\hline 14 & 0 & 0 & +1 & 0.63 & 529 \\
\hline 15 & 0 & 0 & 0 & 0.61 & 514 \\
\hline
\end{tabular}

The governing factors are diamond tip radius $r$, burnishing force $F_{b}$ and feed rate $f$. The variation levels of the chosen governing factors are listed in Table 4.

Table 4. Governing factors and variation levels

\begin{tabular}{lllll}
\hline & & \multicolumn{2}{l}{ Factor levels coded as } \\
\cline { 2 - 5 } Governing factor & & -1 & 0 & +1 \\
\hline Radius $r, \mathrm{~mm}$ & $x_{1}$ & 1 & 2 & 3 \\
Burnishing force $F_{b}, N$ & $x_{2}$ & 200 & 400 & 600 \\
Feed rate $f, \mathrm{~mm} / \mathrm{rev}$ & $x_{3}$ & 0.1 & 0.2 & 0.3 \\
\hline
\end{tabular}

The objective functions $Y_{d_{c}}$ and $Y_{\max \sigma_{t}^{r e s}}$ obtained on the basis of FEM results are shown in Table 3. A regression analysis was performed on the FEM results listed in Table 3 using the QStatLab package (Vuchkov and Vuchkov, 2009). The coefficients of the obtained regression polynomial models for $Y_{d_{c}}$ and $Y_{\max \sigma_{t}^{r e s}}$ are listed in Table 5.

Table 5. Coefficients $b_{i j k}$ of the regressional polynomial models

\begin{tabular}{llllllllllllll}
\hline$b_{i j k}$ & $b_{0}$ & $b_{1}$ & $b_{2}$ & $b_{3}$ & $b_{11}$ & $b_{22}$ & $b_{33}$ & $b_{12}$ & $b_{13}$ & $b_{23}$ & $b_{112}$ & $b_{113}$ & $b_{123}$ \\
\hline$Y_{d_{c}}$ & 0.604 & -0.15 & 0.283 & 0.034 & 0.041 & -0.04 & - & - & - & 0.023 & - & - & - \\
$Y_{\max \sigma_{t}^{r e s}}$ & 520 & 42.1 & -68 & 23 & 20.5 & 24.5 & -15.5 & - & - & - & - & - & \\
\end{tabular}

The following optimization task is formulated and solved. The objective functions $Y_{i}$ and the limiting ones $L_{j}$ are given

$\{Y(\{X\})\}=\left[\begin{array}{llll}Y_{1} & Y_{2} & \ldots & Y_{n}\end{array}\right]^{T} ;\{L(\{X\})\}=\left[\begin{array}{llll}L_{1} & L_{2} & \ldots & L_{m}\end{array}\right]^{T}$,

depending on the governing factors

$\{X\}=\left[\begin{array}{llll}X_{1} & X_{2} & \ldots & X_{\ell}\end{array}\right]^{T}$. 
The following dependences are known:

$L_{j^{\prime}}(\{X\}) \leq L_{j^{\prime}, \max } \forall j^{\prime}=1,2, \ldots, m^{\prime}$,

$L_{j^{\prime \prime}}(\{X\}) \geq L_{j^{\prime \prime}, \min } \forall j^{\prime \prime}=1,2, \ldots, m^{\prime \prime}, m^{\prime}+m^{\prime \prime}=m$,

$X_{k, \min } \leq X_{k} \leq X_{k, \max } ;\{X\} \in \prod_{X}$.

The numerical vector $\left\{X^{*}\right\}$ has to be found, for which the objective functions set $Y_{i}\left\{X^{*}\right\}$ $\forall i=1,2, \ldots, n$ will satisfy a complex of trade-off requirements. In the ideal case:

$Y_{i^{\prime}}\left\{X^{*}\right\}=Y_{i^{\prime}, \min } ; Y_{i^{\prime \prime}}\left\{X^{*}\right\}=Y_{i^{\prime \prime}, \max }, i^{\prime}+i^{\prime \prime}=i \quad \forall i=1,2, \ldots, n$, where $\left\{X^{*}\right\} \in \prod_{X}$.

The vector optimization criterion is:

$\{Y(\{X\})\}=\left[\begin{array}{ll}Y_{d_{c}} & Y_{\max \sigma_{t}^{r e s}}\end{array}\right]^{T}$,

where the objective functions are presented by the regressional polynomial models.

The two functions need to have a maximum. The governing parameters and their limits are respectively:

$\{X\}^{T}=\left[\begin{array}{lll}r & F_{b} & f\end{array}\right]$,

$1 \mathrm{~mm} \leq r \leq 3 \mathrm{~mm} ; 200 \mathrm{~N} \leq F_{b} \leq 600 \mathrm{~N} ; 0.1 \mathrm{~mm} / \mathrm{rev} \leq f \leq 0.3 \mathrm{~mm} / \mathrm{rev}$.

The limiting functions are not defined.

The optimization task was solved by means of QStatLab package. The genetic algorithm with 2500 iterations was used. The optimal governing factor combination, which corresponds to Pareto optimal solutions, is: $r^{*}=1.02 \mathrm{~mm}, F_{b}^{*}=598 \mathrm{~N}, f^{*}=0.29 \mathrm{~mm} / \mathrm{rev}$, where the objective function magnitudes are: $Y_{d_{c}}=1.085 \mathrm{~mm}, \mathrm{Y}_{\max \sigma_{\mathrm{t}}^{\text {res }}}=540.66 \mathrm{MPa}$.

\section{Conclusions}

In this work, the processing rail-end-bolt holes by means of slide diamond burnishing and the effect of the process parameters on the residual hoop stress distribution around the holes have been studied both experimentally and numerically by FEM. These intentionally introduced residual compressive stresses increase the fatigue life of rail-end-bolt holes and, on the whole, of bolted joint railroads, as they significantly slow down fatigue cracks growth and respectively fatigue failure. The basic outcomes can be summarized as follows:

- An innovative combined tool (drill-reamer) and a slide diamond burnishing device for bilateral work have been designed and experimentally investigated.

- The residual hoop stresses have been determined experimentally by modified split ring method based on a stress relief approach.

- In order to build a reliable FE model, the flow stress model has been established by means of a combined approach - indentation test and subsequent FE analyses. The adequacy of this model has been demonstrated with both KE models - 2D and 3D through a comparison of the load-depth curves obtained by an indentation test and FEM simulations.

- FE simulations of residual hoop stress formation by both 2-D and 3-D FE models have been carried out by using the conditions selected for the experiment. On the basis of a comparison with the experimentally obtained results, a 2-D FE model has been chosen for subsequent simulations. 
- The effects of slide diamond burnishing process parameters on residual hoop stress distribution have been analyzed numerically. It has been established that:

- The smaller radius and larger burnishing force lead to larger depth of the compressive zone. However, there is a tendency for a slight increase in the absolute value of the maximum compressive residual stress.

- Larger feed rate leads to an increase in the depth of the compressive zone and an increase in the absolute value of the maximum compressive residual stress.

- The optimal value of the process parameters (governing factors) have been found through a numerical planned experiment and subsequent multi-objective optimization in terms of the characteristics of the zone with residual compressive hoop stresses - maximum depth and the maximum absolute value of compressive residual stress.

\section{Funding}

This work was supported by the Bulgarian Ministry of Education and Science and the Technical University of Gabrovo under contract M-1402/2014.

\section{References}

Belgasim, O. \& El-Axir, M.H. (2010). Modeling of Residual Stresses Induced in Machining Aluminum Magnesium Alloy (Al-3Mg). In: Proceedings of the World Congress on Engineering 2010, Vol II WCE 2010, June 30 - July 2 , London, U.K.

Birger, I.A. (1963). Residual stresses. Moscow: Mashgiz. (In Russian)

Cai, W., Wen, Z., Jin, X., \& Zhai, W. (2007). Dynamic stress analysis of rail joint with height difference defect using finite element method. Engineering Failure Analysis, 14(8), 1488-1499.

Davidenkov, N.N. (1931). Measurement of residual stresses in tubes. Journal of Technical Physics, 1(1), 257-273. (In Russian)

Deng, W. J., Xia, W., Zhou, Z. Y., Chen, W. P., \& Li, Y. Y. (2004, September). Finite element analysis of effects of ball burnishing parameters on residual stresses. In Materials Science Forum (Vol. 471, pp. 658-662).

Duncheva, G. V., \& Maximov, J. T. (2013). A new approach to enhancement of fatigue life of railend-bolt holes. Engineering Failure Analysis, 29, 167-179.

El-Axir, M. H. (2000). An investigation into roller burnishing. International Journal of Machine Tools and Manufacture, 40(11), 1603-1617.

El-Axir, M. H. (2002). A method of modeling residual stress distribution in turning for different materials. International Journal of Machine Tools and Manufacture, 42(9), 1055-1063.

El-Khabeery, M. M., \& Fattouh, M. (1989). Residual stress distribution caused by milling. International Journal of Machine Tools and Manufacture, 29(3), 391-401.

Fattough, M., \& El-Khabeery, M. M. (1989). Residual stress distribution in burnishing solution treated and aged 7075 aluminium alloy. International Journal of Machine Tools and Manufacture, 29(1), 153-160.

Frisch, J., \& Thomsen, E. G. (1951). Residual grinding stresses in mild steel. Trans. ASME, 73, 337345.

Klocke, F., Bäcker, V., Wegner, H., \& Zimmermann, M. (2011). Finite element analysis of the roller burnishing process for fatigue resistance increase of engine components. Proceedings of the Institution of Mechanical Engineers, Part B: Journal of Engineering Manufacture, 225(1), 2-11.

Korzynsky, M. (2013). Slide diamond burnishing, in: Korzynski, M. (Ed), Nonconventional Finishing Technologies. Polish Scientific Publishers, Warsaw, pp. 9-33. 
Maximov, J. T., Duncheva, G. V., \& Ganev, N. (2012). Enhancement of fatigue life of net section in fitted bolt connections. Journal of Constructional Steel Research, 74, 37-48.

Maximov, J.T., \& Duncheva, G.V. (2012). Finite Element Analysis and optimization of spherical motion burnishing of low-alloy steel. Proceedings of the Institution of Mechanical Engineers, Part C: Journal of Mechanical Engineering Science, 226(1), 161-176.

Maximov, J. T., Duncheva, G. V., \& Amudjev, I. M. (2013). A novel method and tool which enhance the fatigue life of structural components with fastener holes. Engineering Failure Analysis, 31, 132-143.

Maximov, J. T., Duncheva, G. V., Ganev, N., \& Amudjev, I. M. (2014). Modeling of residual stress distribution around fastener holes in thin plates after symmetric cold expansion. Journal of the Brazilian Society of Mechanical Sciences and Engineering, 36(2), 355-369.

Maximov, J. T., Duncheva, G. V., Ganev, N., \& Bakalova, T. N. (2009). The benefit from an adequate finite element simulation of the cold hole expansion process. Engineering Failure Analysis, 16(1), 503-511.

Reid, L. (1993). Beneficial residual stresses at bolt holes by cold expansion. In Rail Quality and Maintenance for Modern Railway Operation (pp. 337-347). Springer Netherlands.

Roettger, K. (2002). Walzen hartgedrehter oberflaechen, PhD Thesis, WZL, RWTH Aachen, University, Aachen, Germany.

Sachs, G. (1927). Der Nachweis Inneres Spannungen in Stangen und Rohren. Zeitschrift fur Metalkunde, 19, 352. (In German)

Sadat, A. B., \& Bailey, J. A. (1985). Residual stress distribution in machining an annealed bearing bronze. International journal of mechanical sciences, 27(11), 717-724.

Sadat, A.B. (2012). Surface integrity when machining metal matrix composites, in: Davim, J.P. (Ed), Machining of Metal Matrix Composites. Springer-Verlag, London, pp. 51-61.

Sai, W. B., \& Saï, K. (2005). Finite element modeling of burnishing of AISI 1042 steel. The International Journal of Advanced Manufacturing Technology, 25(5-6), 460-465.

Sartkulvanich, P., Altan, T., Jasso, F., \& Rodriguez, C. (2007). Finite element modeling of hard roller burnishing: an analysis on the effects of process parameters upon surface finish and residual stresses. Journal of Manufacturing Science and Engineering, 129(4), 705-716.

Torabi, A., \& Aliha, M. (2013). Determination of permissible defect size for solid axles loaded under fully-reversed rotating bending. Engineering Solid Mechanics, 1(1), 27-36.

Valkov R., Grozdanov T. (2009). State-of-the-art and problems in structural elements in railways. Mechanics, Transport and Communications, 3, 56-61 (in Bulgarian).

Vitman, F.F. (1935). On the calculation of residual stresses in thick-walled pipes. Journal of Technical Physics, 5(9), 239-247. (In Russian)

Vuchkov, I. N. \& Vuchkov, I. I. (2009). QstatLab Professional, v. 5.5 - Statistical Quality Control Software. User's Manual, Sofia.

Webster, G. A., \& Ezeilo, A. N. (2001). Residual stress distributions and their influence on fatigue lifetimes. International Journal of Fatigue, 23, 375-383.

Yatzenko, V.K., Zaitzev, G.Z., Pritchenko, V.F., \& Ivshtenko L.I. (1985). Enhancement of loadcarrying capacity of machine components by diamond burnishing. Moscow: Machinostroenie (in Russian)

Yen, Y. C., Sartkulvanich, P., \& Altan, T. (2005). Finite element modeling of roller burnishing process. CIRP Annals-Manufacturing Technology, 54(1), 237-240.

Zhuang, W., \& Wicks, B. (2004). Multipass low-plasticity burnishing induced residual stresses: three-dimensional elastic-plastic finite element modelling. Proceedings of the Institution of Mechanical Engineers, Part C: Journal of Mechanical Engineering Science, 218(6), 663-668. 